\title{
Clinical Evaluation, STOP BANG, Epworth Somnolence Scale and Polyssonography Indexes helps OSAS Screen in Patients with Sleep Complaints: Our Experience in Rio De Janeiro State
}

\author{
Migueis D*, Simas C, Parma M, Sabaneeff L, Joffily L and Araujo-Melo MH \\ Gafree and Guinle University Hospital, Brazil \\ *Corresponding author: Migueis D, Debora Petrungaro, Gafree Hospital, Brazil
}

\section{ARTICLE INFO}

Received: 慧 February 09, 2019

Published: 豐 February 19, 2019

Citation: Migueis D, Simas C, Parma M, Sabaneeff L, Joffily L and Araujo-Melo MH. Clinical Evaluation, STOP BANG, Epworth Somnolence Scale and Polyssonography Indexes helps OSAS Screen in Patients with Sleep Complaints: Our Experience in Rio De Janeiro State. Biomed J Sci \& Tech Res

ABSTRACT

The aims of this study were to correlate STOP BANG score, Epworth Somnolence Scale and desaturation to OSA in a population with sleep complaints from a public reference hospital and to highlight OSA severity features in this mixed ethnic population. The median apnea-hypopnea index (AHI) was 23.8/hour in men and 11.2/hour in women. Although obesity, snoring, and sleepiness were similar features in both genders, the AHI and Oxygen Desaturation Index were significantly higher in men, as in epidemiological studies. Furthermore, after bivariate correlation, the AHI was associated with oxygen desaturation, which is responsible for cardiovascular and cognitive consequences, and also with body mass index, snore, and neck circumference, summarized in STOP BANG criteria. It is undeniable that the high prevalence of those with sleep complaints is an important health problem and our data suggest that pulse oximetry, and STOP BANG score, may be used to screen adults with sleep complaints.
\end{abstract} 14(5)-2019. BJSTR. MS.ID.002609.
Keywords: Sleepiness; Obstructive Sleep Apnea Syndrome; Sleep Disorders; Gender Differences

\section{Introduction}

Obstructive sleep apnea (OSA) is an important public health issue, since epidemiological studies and observations of OSA patients have consistently shown the prevalence of hypertension, type II diabetes, cardiovascular disease, and stroke to be higher in this population (SOMERS 2008). Mental conditions and carotid plaque burden are also associated with low oxygen saturation related to sleep-disordered breathing (SDB) [1,2] OSA derives not only relevant consequences but also presented high prevalence in many studies. According to the population-based study of Hipnolaus in Switzerland, the prevalence of moderate-to-severe SDB ( $\geq 15$ events per hour) was $23.4 \%$ in women and $49.7 \%$ in men, which was associated with hypertension, metabolic syndrome, diabetes, and depression [3]. Besides, of 1,042 volunteers selected independently of sleep complaints in São Paulo, OSA was observed in $32.8 \%$ and associated with obesity and male sex [4]. The aims of this study were to correlate STOP BANG score, Epworth Somnolence Scale and desaturation to OSA in a Rio de Janeiro population with sleep complaints from a public reference hospital and to highlight OSA severity features in this population.

\section{Methods}

This retrospective analysis assessed OSAS severity and the profile of adults with sleep complaints from our database after Research Ethics Committee approval (CAAE 42785214.1.0000.5258). A total of 185 patients with sleep complaints aged 18 to 80 years old (yo) were included. They were systematically evaluated between April 2015 and December 2017 in the sleep ambulatory with a physical exam, translated and validated questionnaires (Epworth Sleepiness Scale [ESS] [5,6] and STOP BANG score [7-9], and laboratory polysomnography studies. Exclusion criteria were: Polyneuropathy; 
active heart and lung diseases; craniofacial malformations; immunodeficiency; systemic vasculitis; and neoplasia. We used the 2015 Portuguese version of STOP-BANG [7-9] to measure the risk of OSA, whereby three or more affirmative answers indicated a high risk of OSA [8,9] and the Epworth Sleepiness Scale (ESS) [6] to measure diurnal somnolence. In the ESS, sleep propensity was measured in 8 routine situations on a scale from 0 (indicating no chance of falling asleep) to 3 (indicating a high chance of dozing off). The final score ranged from 0 to 24 points accordingly, with excessive diurnal somnolence being defined as a score higher than 10 [6].

Polysomnography parameters: The subjects underwent transcutaneous pulse oximetry, with the respiratory effort recorded using inductance plethysmography. Apnea was measured by an oronasal thermistor and was defined as a drop in baseline airflow by $90 \%$ or more for at least 10 seconds. Hypopnea was measured by a nasal pressure cannula and was defined as a partial obstructive event with airflow drop by more than $30 \%$ from baseline for at least 10 seconds. Besides, hypopnea was also considered present with oxygen desaturation of $3 \%$ or more, with electroencephalographically confirmed arousal. The polysomnography data were measured based on polysomnography recordings (EMSA Equipamentos Médicos, Rio de Janeiro, Brazil). OSAS criteria using the Apnea-Hypopnea Index (AHI) of 5 or higher were defined according to the American Academy Sleep Manual. Our data were analyzed

Table 1: Patients Demographics. with SPSS 13.0 for Windows. The continuous variables distribution between groups was compared by the Mann-Whitney U test. Categorical variables comparison was performed by Chi-square or Fisher test when indicated. Correlations were performed by Spearman Correlation Coefficient. The significance level was fixed at 5\%.

\section{Results}

A total of 114 subjects (67 men, 58.8\%) were included in this study. The median age was 53.0 yo; median BMI $=30.4 \mathrm{~kg} / \mathrm{m} 2$ and median ESS score=12.0 (Table 1). In this population, there were predominantly men with significantly lower age $(\mathrm{P}<.001)$, higher median AHI ( $\mathrm{P}=.009)$, and higher median STOP BANG score $(\mathrm{P}<.001)$ than the women's group (Table 1). Table 2 showed that the prevalence of systemic hypertension in women was four times higher than in men ( $\mathrm{P}=.0001)$. Despite high body mass index (BMI), type II diabetes prevalence was low in both genders. Although both groups reported snore and somnolence, there was a low prevalence of enlarged tongue, retrognathism, tonsil hypertrophy, and Mallampati grades 3 or 4 (Table 2). In Table 3, AHI, Respiratory Disturbance Index (RDI), and Oxygen Desaturation Index (ODI) were significantly higher in men. The Rapid Eyes Movement (REM) percentage was reduced and the arousal index was elevated in all groups (Table 3). The AHI was correlated with sleep time spent below 90\% oxygen saturation $(\mathrm{T}<90 \%)$, lowest 02 saturation, ODI, cervical circumference, ESS score, STOP BANG, and BMI (Table 4 and Figure 1).

\begin{tabular}{|c|c|c|c|c|}
\hline \multirow{4}{*}{ Profile } & Total & Woman & Man & \multirow{4}{*}{$P$ value } \\
\hline & $(\mathrm{N}=114)$ & $(\mathrm{N}=47)$ & $(\mathrm{N}=67)$ & \\
\hline & Median & Median & Median & \\
\hline & (minimum-maximum) & (minimum-maximum) & (minimum-maximum) & \\
\hline BMI & 30.4 & 31.2 & 30.1 & \multirow{2}{*}{0.584} \\
\hline$\left(\mathrm{kg} / \mathrm{m}^{2}\right)$ & $(21.5-55.8)$ & $(22.0-46.3)$ & $(21.5-55.8)$ & \\
\hline \multirow{2}{*}{ ESS } & 12 & 12 & 12 & \multirow{2}{*}{0.797} \\
\hline & $(0.0-24.0)$ & $(0.0-24.0)$ & $(1.0-24.0)$ & \\
\hline Age & 53 & 56 & 48 & \multirow{2}{*}{$<0.001^{*}$} \\
\hline (years old) & $(20.0-79.0)$ & $(36.0-79.0)$ & $(20.0-67.0)$ & \\
\hline STOP BANG & $4.0(0-8.0)$ & $1(0-7.0)$ & $5.0(1.0-8.0)$ & $<0.001^{*}$ \\
\hline AHI & 15.3 & 11.2 & 23.8 & \multirow{2}{*}{$0.009^{*}$} \\
\hline (events/hour) & $(0.0-92.3)$ & $(0.3-92.32)$ & $(0.0-86.4)$ & \\
\hline OSAS Severity & $\mathrm{N}(\%)$ & $\mathrm{N}(\%)$ & $\mathrm{N}(\%)$ & $P$ value \\
\hline Absence & $11(9.6)$ & $10(21.3)$ & $1(1.5)$ & $0.013^{*}$ \\
\hline Mild & $45(39.5)$ & $20(42.6)$ & $25(37.3)$ & $0.002^{*}$ \\
\hline Moderate & $24(21.1)$ & $9(19.1)$ & $15(22.4)$ & 0.058 \\
\hline Severe & 34 (29.8) & $8(17.0)$ & $26(38.8)$ & 0.253 \\
\hline
\end{tabular}

Note: BMI: Body Mass Index (National Heart, Lung and Blood Institute); ESS: Epworth Somnolence Scale; AHI: Apnea-Hypopnea Index; OSAS: Obstructive Sleep Apnea Syndrome; *statistically significant. 
Table 2: Population with sleep complaints medical evaluation.

\begin{tabular}{|c|c|c|c|c|}
\hline Profile & Women $(\mathrm{N}=47)$ & $\operatorname{Men}(\mathrm{N}=67)$ & P value & OR $(95 \% \mathrm{CI})$ \\
\hline \multicolumn{5}{|c|}{ Cervical circumference } \\
\hline$>40 \mathrm{~cm}$ & $9(19.6)$ & $40(66.7)$ & $0,000^{*}$ & $0.122^{*}$ \\
\hline$\leq 40 \mathrm{~cm}$ & $37(80.4)$ & $20(33.3)$ & & $(0.49-0.30)$ \\
\hline \multicolumn{5}{|c|}{ Systemic Hypertension } \\
\hline Yes & $38(80.9)$ & $32(48.5)$ & $0.001^{*}$ & $4.48^{*}$ \\
\hline No & $9(19.1)$ & $34(51.5)$ & & $(1.87-10.73)$ \\
\hline \multicolumn{5}{|c|}{ DM II } \\
\hline Yes & $10(14,9)$ & $12(26.1)$ & 0.145 & 2.01 \\
\hline No & $57(85,1)$ & $34(73.9)$ & & $(0.78-5.15)$ \\
\hline \multicolumn{5}{|c|}{ Mallampati } \\
\hline 3,4 & $26(65.0)$ & $28(46,7)$ & 0.057 & 1.1 \\
\hline 1,2 & $14(35.0)$ & $32(53,3)$ & & $(0.79-1.53)$ \\
\hline \multicolumn{5}{|c|}{ Tonsils } \\
\hline 3,4 & $3(6.5)$ & $10(16.4)$ & 0.134 & 0.36 \\
\hline $0,1,2$ & 43 (93.5) & $51(83.6)$ & & $(0.09-1.37)$ \\
\hline \multicolumn{5}{|c|}{ Enlarged tongue } \\
\hline Yes & $19(45.2)$ & $21(32.8)$ & 0.198 & 1.69 \\
\hline No & $23(54.8)$ & $43(67.2)$ & & $(0.76-3.77)$ \\
\hline \multicolumn{5}{|c|}{ Retrognathism } \\
\hline Yes & $11(25.0)$ & $13(20.0)$ & 0.537 & 1.33 \\
\hline No & $33(75.0)$ & $52(80.0)$ & & $(0.54-3.33)$ \\
\hline \multicolumn{5}{|c|}{ BMI } \\
\hline$\geq 30$ & $28(60.9)$ & $35(52.2)$ & 0.365 & 0.703 \\
\hline$<30$ & $18(39.1)$ & $32(47.8)$ & & $(0.33-1.51)$ \\
\hline \multicolumn{5}{|c|}{ Snore complaint } \\
\hline Yes & $43(93.0)$ & $63(94.0)$ & 0.603 & 0.683 \\
\hline No & $4(8.5)$ & $4(6.0)$ & & $(0.16-2.88)$ \\
\hline \multicolumn{5}{|c|}{ Somnolence (ESS) } \\
\hline Yes & $29(61.7)$ & $41(61.2)$ & 0.956 & 0.979 \\
\hline No & $18(38.3)$ & $26(38.8)$ & & $(0.46-2.11)$ \\
\hline
\end{tabular}

Note: DMII: Diabetes Mellitus type 2; *statistically significant; BMI: Body Mass Index; ESS: Epworth Somnolence Scale.

Table 3: Polysomnography Date.

\begin{tabular}{|c|c|c|c|c|c|}
\hline & Total $(\mathrm{N}=114)$ & Woman $(\mathrm{N}=48)$ & Men & & OR \\
\hline Polysomnography Date & Median (minimum-maximum) & $\begin{array}{c}\text { Median (minimum-maxi- } \\
\text { mum) }\end{array}$ & $\begin{array}{c}(\mathrm{N}=67) \\
\text { Median (minimum-max- } \\
\text { imum) }\end{array}$ & $P$ value & (IC 95\%) \\
\hline AHI & 15.35 & 11.5 & 23.76 & \multirow{2}{*}{$0.009^{*}$} & $0.97^{*}$ \\
\hline (events/hr) & $(0-92.32)$ & $(0.31-92.32)$ & $(0-86.39)$ & & $(0.95-0.99)$ \\
\hline RDI & 15.34 & 11.49 & 23.69 & \multirow[b]{2}{*}{$0.004^{*}$} & $0.96^{*}$ \\
\hline (events/hr) & $(0-87.84)$ & $(0.31-87.84)$ & $(0-86.39)$ & & $(0.93-0.99)$ \\
\hline
\end{tabular}




\begin{tabular}{|c|c|c|c|c|c|}
\hline ODI & 4.18 & 1.92 & 9.28 & \multirow[b]{2}{*}{$0.014^{*}$} & $0.94^{*}$ \\
\hline (events/hr) & $(0-80.57)$ & $(0-54.94)$ & $(0-80.57)$ & & (0.94-0.99) \\
\hline $\mathrm{T}<90 \%$ & 2.22 & 0.94 & 2.65 & \multirow{2}{*}{0.09} & 0.97 \\
\hline$(\%)$ & $(0-58.19)$ & $(0-57.23)$ & $(0-58.19)$ & & $(0.94-1.01)$ \\
\hline \multirow{2}{*}{$\begin{array}{l}\text { Arousal Index (events/ } \\
\text { hr) }\end{array}$} & 17.21 & 15.7 & 17.65 & \multirow[b]{2}{*}{0.131} & 0.98 \\
\hline & $(0.85-116.39)$ & (5.59-91.47) & $(0.85-116.39)$ & & $(0.96-1.01)$ \\
\hline N3 Percentual & 17 & 16.87 & 17.67 & \multirow{2}{*}{0.404} & 0.98 \\
\hline$(\%)$ & $(0-53.40)$ & $(0-43.00)$ & $(0-53.40)$ & & $(0.95-1.02)$ \\
\hline \multirow{2}{*}{ REM Percentual (\%) } & 12 & 10.88 & 13 & \multirow{2}{*}{0.461} & 0.98 \\
\hline & $(0-30.78)$ & $(0-30.78)$ & $(0-30.16)$ & & $(0.93-1.03)$ \\
\hline \multirow{2}{*}{$\begin{array}{c}\text { Lowest } \mathrm{O}_{2} \text { Saturation } \\
(\%)\end{array}$} & 80 & 81.5 & 78 & \multirow{2}{*}{0.059} & 1.04 \\
\hline & $(50.00-93.00)$ & $(50.00-93.00)$ & $(50.00-92.00)$ & & $(0.99-1.08)$ \\
\hline \multirow{2}{*}{ RERA Index (events/hr) } & 0 & 0 & 0 & \multirow{2}{*}{0.114} & 1.74 \\
\hline & $(0-17.66)$ & $(0-17.66)$ & $(0-4.0)$ & & $(0.87-3.45)$ \\
\hline
\end{tabular}

Note: AHI: Apnea-Hypopnea Index; RDI: Respiratory Disturbance index; ODI: oxygen desaturation index; $\mathrm{O}_{2}$ : Oxygen; T<90\%: sleep time spent below $90 \%$ oxygen saturation; *statistically significant.
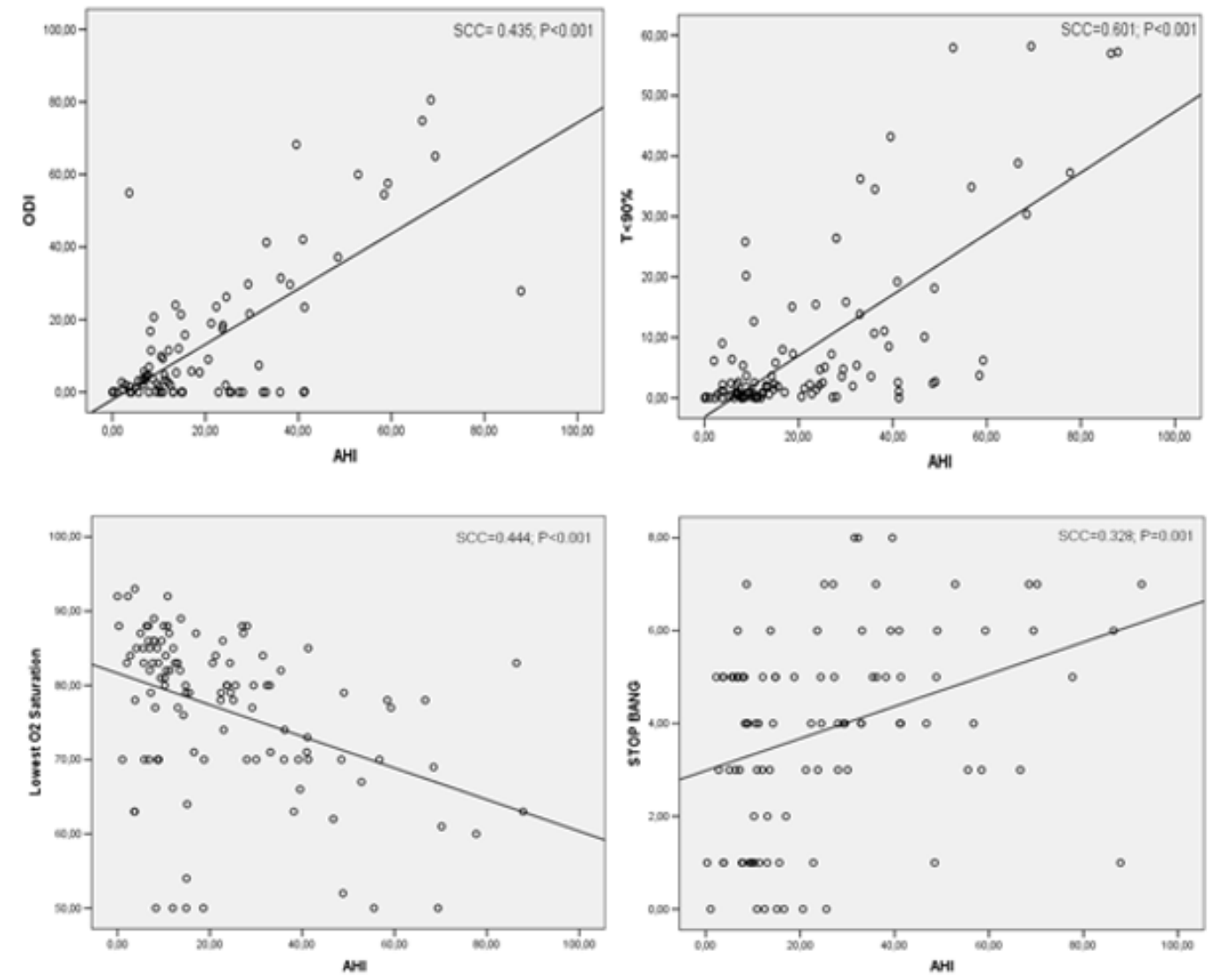

Figure 1: Correlation of Apnea-hypopnea index with Oxyhemoglobin saturation and STOP BANG.

Note: $\mathrm{O}_{2}$ : Oxygen; $<<90 \%$ : Sleep time spent below 90\% oxygen saturation; ODI: Oxygen Desaturation Index; AHI: Apneahypopnea index; SCC: Spearman Correlation Coefficient. 
Table 4: Correlation of Apnea-hypopnea index with others sleepy parameters.

\begin{tabular}{|c|c|c|}
\hline AHI and others parameters Correlation & Spearman Correlation Coefficient & P value \\
\hline T $<90 \%$ & 0.601 & $<0.001^{*}$ \\
\hline Lowest $\mathrm{O}_{2}$ Saturation & 0.444 & $<0.001^{*}$ \\
\hline Oxygen Desaturation Index & 0.435 & $<0.001^{*}$ \\
\hline Cervical Circumference & 0.422 & $<0.001^{*}$ \\
\hline Epworth Somnolence Scale & 0.344 & $<0.001^{*}$ \\
\hline STOP BANG & 0.328 & $0.001^{*}$ \\
\hline Body Mass Index (kg/m $\mathrm{m}^{2}$ & 0.227 & $0.015^{*}$ \\
\hline Age (years old) & -0.037 & 0.693 \\
\hline
\end{tabular}

Note: $\mathrm{SatO}_{2}$ : Oxyhemoglobin saturation; $\mathrm{O}_{2}$ : Oxygen; $\mathrm{T}<90 \%$ : sleep time spent below $90 \%$ oxygen saturation; AHI: Apnea-hypopnea index; *statistically significant.

\section{Discussion}

This is the first profile of the population with sleep complaints in Rio de Janeiro. It is a specific mixed ethnic population, different from homogeneous populations from other countries. The ODI, AHI, and RDI were significantly higher in men, who had increased prevalence of OSA risk factors, such as large neck circumference, obesity, male gender, and snore. These features are included in STOP BANG score and previous studies performed in homogeneous populations had already suggested this tool for population screening [10-12]. After bivariate correlation, the AHI was associated with these classic risk factors (cervical circumference, STOP BANG, and BMI), and also with oxygen desaturation ( $\mathrm{T}<90 \%$, ODI, and the lowest 02 saturation), as Guilleminault and cols. (1988) had already reported. Besides, the AHI was correlated to the ESS in this study, as somnolence is a known consequence of moderate and severe OSAS [14]. In our study, there was a low prevalence of hypertrophied tonsils, enlarged tongue, and retrognathism in both genders, despite snore and somnolence were presented in high prevalence. In the current study, although obstructive events associated with oxygen desaturation were higher in men, both genders had a high arousal index and reduced REM percentage, which shows impaired sleep architecture due to sleep fragmentation [14].

Although $\mathrm{AHI}<15$ was prevalent among women, their snore complaint and ESS score were similar to men's, as previous literature [11,12]. Epidemiological studies have shown that OSAS has been predominantly a disease of obese middle-aged men, and it is generally twice as common in men, in order to women's OSAS begins after menopause14. The clinical study with 2,827 patients suggests that the severity of the disease is lower in females and is more associated with nocturnal choking, morning headache, fatigue, insomnia symptoms, and impaired memory, while men experienced more witnessed apnea [11]. Shepertycky and cols. (2005) also have described different tolerance of symptoms and clinical OSAS presentation between genders, such as fatigue, insomnia, and depression [12]. These findings suggest that women at the same AHI level may be under-evaluated for OSAS, using STOP BANG as the reference. Whereas obesity and diabetes prevalence were similar characteristics between genders, systemic hypertension was 4.48 times as likely in women, although OSAS severity was lower than men. However, in previous literature, hypertension and diabetes were also more common in women [11]. One limitation of this study is that transversal studies should not determine OSAS consequences. Besides, additional studies are necessary to compare sensitivity, specificity and predictive values to clinical consequences.

\section{Conclusion}

In conclusion, our data suggest that pulse oximetry, and STOP BANG score, may be used to screen this mixed ethnic population in adults with sleep complaints in order to prevent cognitive and cardiovascular effects.

\section{Acknowledgment}

The authors gratefully acknowledge the sleep laboratory team.

\section{Funding}

This research did not receive any specific grant from funding agencies in the public, commercial, or not-for-profit sectors.

\section{References}

1. Appleton SL, Gill TK, Lang CJ, Taylor AW, McEvoy RD, et al. (2018) Prevalence and comorbidity of sleep conditions in Australian adults: 2016 Sleep Health Foundation national survey. Sleep Health 4: 13-19.

2. Gunnarsson SI, Peppard PE, Korcarz CE, Barnet JH, Hagen EW, et al. (2015) Oxygen saturation and atherosclerosis Minimal nocturnal oxygen saturation predicts future subclinical carotid atherosclerosis: the Wisconsin sleep cohort. J Sleep Res 24: 680-686.

3. Heinzer R, Vat S, Marques-Vidal P, Marti-Soler H, Andries D, et al. (2015) Prevalence of sleep-disordered breathing in the general population : the HypnoLaus study. Lancet Respir Med 3:310-318.

4. Tufik S, Santos-Silva R, Taddei JA, Bittencourt, LR (2010) Obstructive sleep apnea syndrome in the Sao Paulo Epidemiologic Sleep Study. Sleep Med 11: 441-446.

5. Johns M (1991) A New Method for Measuring Daytime Sleepiness: The Epworth Sleepiness Scale. Sleep 14: 540-545.

6. Bertolazi AN, Fagondes SC, Hoff LS, Pedro VD, Barreto SMB, et al. (2009) Portuguese-language version of the Epworth sleepiness scale: validation for use in Brazil. J Bras Pneumol 35: 877-883. 
7. Chung F, Subramanyam R, Liao P (2012) High STOP-Bang score indicates a high probability of obstructive sleep apnoea. Br J Anaesth 108: 768775 .

8. Reis R, Teixeira F, Martins V (2015) Validation of a Portuguese Version of the STOP-Bang Questionnaire as a Screening Tool for Obstructive Sleep Apnea: Analysis in a Sleep Clinic. Rev Port Pneumol 21: 61-68.

9. Boynton G, Vahabzadeh A, Hammoud S (2013) Validation of the STOPBANG Questionnaire among Patients Referred for Suspected Obstructive Sleep Apnea. J Sleep Disor: Treat Care 2: 4.

10. Young T (1993) Analytic Epidemiology Studies of Sleep Disordered Breathing-What Explains the Gender Difference in Sleep Disordered Breathing? Sleep 16: S1-S2.

\section{ISSN: 2574-1241}

DOI: 10.26717.BJSTR.2019.14.002609

Migueis D. Biomed J Sci \& Tech Res

(C) This work is licensed under Creative

Submission Link: https://biomedres.us/submit-manuscript.php
11. Basoglu OK, Tasbakan MS (2018) Gender differences in clinical and polysomnographic features of obstructive sleep apnea : a clinical study of 2827 patients. Sleep Breath 22: 241-249.

12. Shepertycky M, Banno K, Kryger M (2005) Differences between Men and Women in the Clinical Presentation of Patients Diagnosed with Obstructive Sleep Apnea Syndrome. Sleep 28: 309-314.

13. Guilleminault C, Partinen M, Quera-Salva MA, Hayes B, Dement WC, et al. (1988) Determinants of daytime sleepiness in obstructive sleep apnea. Chest 94: 32-37.

14. Young T, Rabago D, Zgierska A, Austin D, Laurel F, et al. (2003) Objective and subjective sleep quality in premenopausal, perimenopausal, and postmenopausal women in the Wisconsin Sleep Cohort Study. Sleep 26: 667-672.

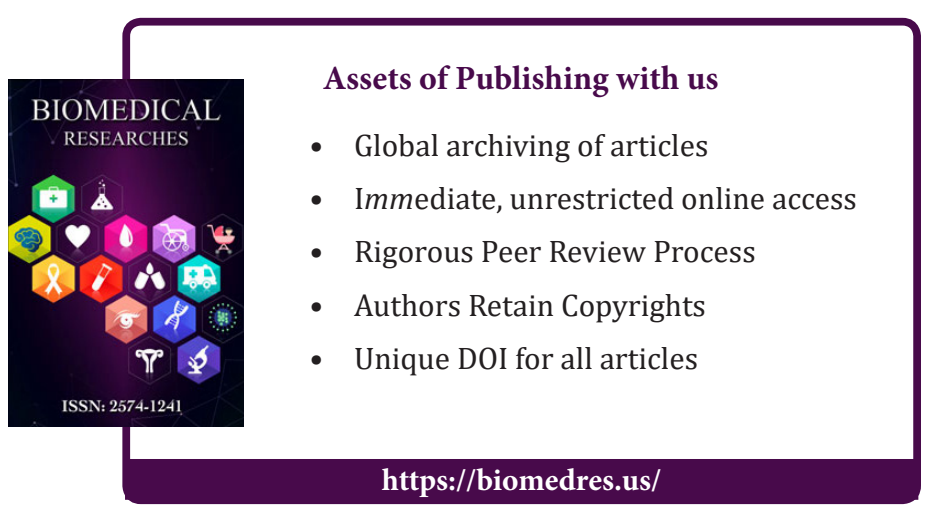

